\title{
Hallazgo de una bula incunable desconocida en la catedral de Valencia. Contribución a la imprenta de Antonio Téllez (Toledo, 1495)*
}

\section{Incunabular papal bull found at the Valencia cathediral archive. Contribution to Antonio Téllez's printing house (Toledo, 1495)}

\author{
José Vicente Boscá Codina \& María Luz Mandingorra Llavata \\ jose.v.bosca@uv.es / m.luz.mandingorra@uv.es \\ Universitat de València
}

Resumen: El objeto de este trabajo es dar a conocer y estudiar la edición de una bula de indulgencias de la Santa Cruzada, de vivos, escrita en catalán e impresa en Toledo en 1495, de la cual se ha hallado un ejemplar en el Archivo de la Catedral de Valencia. De acuerdo con la información disponible a día de hoy se trata de un ejemplar único en el mundo.

Palabras clave: incunables, bula, Antonio Téllez, Catedral de Valencia

Abstract: The aim of this paper is to analyse a copy of a Papal bull granting indulgence for the living. It was issued in favour of the Crusaders, and printed in Toledo in 1495. It is written in Catalan, and has been found in the Valencia Cathedral Archive. We wish to bring its existence to the attention of scholars, as it is the only surviving copy that we know of.

Keywords: incunabula, Papal bull, Antonio Téllez, Valencia Cathedral 
José Vicente Boscá Codina \& María Luz Mandingorra Llavata. Hallazgo de una bula incunable desconocida en la catedral de Valencia. Contribución a la imprenta de Antonio Téllez (Toledo, 1495)

En el Archivo de la Catedral de Valencia, los legajos 6293-4 a 6293-12 incluyen una serie de indulgencias cuyo destinatario era Lluís de Perellós, quien fuera canónigo de dicha Catedral desde 1514 hasta su muerte, ocurrida en 1530. ${ }^{1}$ Concretamente el legajo 6293-11 contiene una bula de indulgencias de la Santa Cruzada, de vivos, escrita en catalán e impresa en Toledo en 1495. El objetivo prioritario del presente trabajo es dar a conocer esta bula, habida cuenta que no aparece recogida en los grandes repertorios y bases de datos especializadas, como el Incunabula Short Title Catalogue (=ISTC) y el Gesamtkatalog der Wiegendrucke (=GW), de lo cual se infiere que se trata de una edición desconocida, de la cual sólo se conserva este ejemplar. Además, mediante su identificación y estudio se pretende contribuir a un mejor conocimiento de la actividad tipográfica de Antonio Téllez en relación con la impresión de bulas durante el período incunable.

Era conocida, no obstante, la versión en castellano de esta misma bula, impresa igualmente en Toledo en 1495. A ella hacía referencia Konrad Haebler en la primera parte de su Bibliografía Ibérica (1903: 45, n ${ }^{\circ}$ 100), a partir de un ejemplar conservado en un archivo particular de España del que no se ofrecía indicación alguna, atribuyendo la impresión de esta bula a Gabriel Téllez. Con anterioridad, según el incunabulista alemán, Cristóbal Pérez Pastor (1887: 10) había recogido tres noticias correspondientes al año 1494, que bien podrían referirse a esta bula en cuestión: « $\ll$. Bula de la Cruzada. 6. Instrucción de la Bula de la Cruzada. 7. Sumario de las indulgencias y estaciones de Roma concedidas por nuestro muy Santo Padre Alejandro VI á los que tomaren la Bula de la Cruzada». Acerca de la fecha de impresión, afirma a renglón seguido este autor:

Como la Bula de la Cruzada concedida por Alejandro VI en 12 de Noviembre de 1494 es la que se conoce como próximamente anterior á la de 1501, hemos asignado á estos impresos la fecha de 1495, aunque bien pudieran haberse impreso algunos ejemplares en fin del año anterior

Aunque en este caso Pérez Pastor (1887: XIX - XX, 10) no hace referencia a impresor alguno, sí menciona a un tal Juan Téllez como tipógrafo activo en Toledo entre los años 1494 y 1495. En relación con estas discrepancias a propósito del nombre del impresor, Esperanza Velasco y José Francisco Egea (1985: 98) plantearon la posibilidad de que Pérez Pastor «al llamarlo Juan, sin duda pensaría en Juan Vázquez, primera persona que, según parece, tuvo a su cargo la imprenta del monasterio toledano». Así mismo, sobre la atribución que hace Haebler afirman que «al hablar de Gabriel Téllez como impresor, tendrá otro lapsus, dando el nombre del fraile conocido con el seudónimo de Tirso de Molina». Por su parte, el Einblattdrucke des XV. Jahrbunderts (1914: 13, n 40) describía nuevamente la bula y, al igual que Pérez Pastor, la atribuía a Juan Téllez. Finalmente, tres años después, en la segunda parte de la Bibliografía Ibérica, Haebler (1917: 29, no 100) corrigió el nombre del impresor por el de Antonio Téllez. La corrección se producía a partir de la aparición de

\footnotetext{
*Esta investigación se ha beneficiado parcialmente del Proyecto de Investigación Financiado por el Ministerio de Economía y Competitividad: Documentación real de la Edad Media conservada en archivos valencianos: edición crítica y estudio (HAR2012-36656)

1 Lluís de Perellós, ordenado sacerdote en 1507, fue igualmente familiar y comensal de Rodrigo de Borja, así como protonotario apostólico desde 1512 (Pons/Cárcel 2005: 943).
}

SCRIPTA, Revista internacional de literatura i cultura medieval i moderna, núm. 5 / juny 2015 / pp. 93 - 104 ISSN: 2340-4841 · doi:10.7203/SCRIPTA.5.5164 
José Vicente Boscá Codina \& María Luz Mandingorra Llavata. Hallazgo de una bula incunable desconocida en la catedral de Valencia. Contribución a la imprenta de Antonio Téllez (Toledo, 1495)

tres ejemplares del De computatione dierum criticarum de Julián Gutiérrez, única obra de este impresor que presenta colofón con indicación de tipógrafo ${ }^{2}$ (fig. 1). Desde este momento no parece existir vacilación alguna respecto al nombre de Antonio Téllez. ${ }^{3}$ En 1985, los ya mencionados Esperanza Velasco y José Francisco Egea dieron a conocer la aparición, en el Archivo Histórico Provincial de Zaragoza, de un nuevo ejemplar de esta bula de indulgencias (fig. 2), el único de la tirada que actualmente queda recogido en las bases de datos de incunables. ${ }^{4}$

Los actuales trabajos de catalogación del fondo de incunables que conserva la Catedral de Valencia, a cargo de los autores de este mismo trabajo, han propiciado el hallazgo del que aquí se da noticia, que nos sitúa ante un ejemplar único en el mundo, tal y como se ha señalado más arriba. Se trata de una hoja volante de $223 \times 313 \mathrm{~mm}$., que cuenta con 42 líneas de texto y con espacio en las líneas $29 / 30$ y 32, para incluir el nombre del beneficiario y la fecha de expedición respectivamente. Está impresa en catalán, en escritura gótica de dos tamaños (98G / ca. 250G), y presenta al pie las firmas xilográficas de Francisco de la Fuente, obispo de Ávila, ${ }^{6}$ y de Diego de Deza, obispo de Salamanca. ${ }^{7}$ A la izquierda, junto a la firma del obispo abulense aparece su sello, igualmente xilográfico. A la derecha, acompañando la firma de Diego de Deza, se encuentra su sello, de cera en este caso. El estado de conservación de esta bula es bueno ya que presenta únicamente algunas manchas de humedad. En el hueco dejado para el nombre del beneficiario se puede leer, en una escritura gótica cursiva: «mosén Luýs de Perellós». Por otra parte, en los espacios reservados para la datación, de la misma mano, figura: «València [a] $V$ [dies de] jullio [de XC e] $V »$. En el vuelto, de otra mano posterior y en escritura humanística cursiva se puede leer: «La indulgèntia de la cruada R.» (figs. 3 y 4).

En relación con los caracteres tipográficos, actualmente atribuidos sin discusión a Antonio Téllez, se han formulado diversas hipótesis. Por un lado, Antonio Odriozola (1982: 171-172), que sitúa este impresor en Toledo, entre 1494 y 1498, afirma que el tipo habitual que utiliza Téllez «es un $98 \mathrm{G}$ algo arcaico, que recuerda a veces al de su predecesor en Toledo Juan Vásquez» (Odriozola,

2 Gutiérrez, Julián. De computatione dierum criticarum. Toledo: Antonio Téllez. 28 marzo, 1495; 4. Véase Haebler (1917: 86, n 314). Ver también GW 12101, ISTC ig00734000.

3 Se puede hacer referencia en este sentido a los trabajos de Vindel (1945-1951) y Odriozola (1982), entre otros. Lo mismo cabe decir de los grandes repertorios como el GW o el ISTC.

4 La bula en cuestión corresponde a GW 62, ISTC ia00374500.

5 A diferencia de la versión en castellano de esta misma bula, que presenta 43 líneas de texto. Véanse Haebler (1903: 45, no 100) y Velasco/Egea (1985: 97).

6 Francisco Sánchez de la Fuente fue obispo de Ávila desde el 23 de enero de 1493. El 27 de enero de 1496 se convirtió en obispo de Córdoba (Eubel 1914: 78, 136).

7 Diego de Deza fue obispo de Salamanca desde el 23 de junio de 1494. El 14 de febrero de 1498 se convirtió en obispo de Jaén (Eubel 1914: 227, 159).

SCRIPTA, Revista internacional de literatura i cultura medieval i moderna, núm. 5 / juny 2015 / pp. 93 - 104 ISSN: 2340-4841 · doi:10.7203/SCRIPTA.5.5164 
José Vicente Boscá Codina \& María Luz Mandingorra Llavata. Hallazgo de una bula incunable desconocida en la catedral de Valencia. Contribución a la imprenta de Antonio Téllez (Toledo, 1495)

1982:171 $)^{8}$. Aunque Odriozola no establece una identidad entre los caracteres de ambos impresores, Juan Delgado (1996: II, 669), por su parte, plantea la posibilidad de que los tipos de Juan Vázquez, activo en Toledo entre 1484 y 1491, pasaran a Antonio Téllez. ${ }^{9}$ Con anterioridad, Francisco García Craviotto (1988: 167-169) había apuntado la posible relación entre Antonio Téllez y Alfonso Fernández de Córdoba, quien habría regresado a Castilla en su última época, teniendo en cuenta que la letrería 98 G, la utilizada por Antonio Téllez, sería una adaptación de la 108 G, diseñada por Fernández de Córdoba.

Cabe, pues, añadir a la nómina de los impresos que salieron del taller de Antonio Téllez, esta edición en catalán de una bula de indulgencias impresa en Toledo en 1495 y cuya versión castellana, tal y como hemos señalado, era ya bien conocida. No será esta la única ocasión en que Antonio Téllez asuma la impresión de las versiones castellana y catalana de una misma bula de indulgencias. Efectivamente, del mismo año son conocidas las dos versiones de otra bula de indulgencias de la Santa Cruzada, en este caso para difuntos,${ }^{10}$ que salieron igualmente del taller del mismo impresor. La observación formal de estos productos muestra un comportamiento idéntico: las bulas para vivos, sean en castellano o en catalán, presentan las mismas características materiales (figs. 2 y 3 ) y lo mismo cabe decir de la fórmula para difuntos (figs. 5 y 6). Situación distinta a la que muestra la impresión de indulgencias por parte de su predecesor, Juan Vázquez, cuando menos a partir de la imagen que ofrecen los materiales conservados. En el caso de este impresor, en las dos bulas de indulgencias para vivos del papa Sixto IV, impresas en 1484, se utiliza un taco xilográfico distinto para el encabezado en sus versiones castellana ${ }^{11}$ y catalana, ${ }^{12}$ aunque el resto de las características

8 Sobre el periodo de actividad del impresor Antonio Téllez, Colin Clair (1998: 117) afirma que «trabajó en Toledo desde 1494 hasta 1497 aproximadamente». La relativa discrepancia está motivada por la incierta datación de la última obra atribuida a este impresor. Así, Haebler (1917: 161, no 583 [5]) sitúa las Coplas a la muerte del príncipe Don Juan en 1498, al igual que Odriozola (1982:172) y el GW M38836, aunque este último indica que se trata de una fecha aproximada. En cambio el ISTC ir00306000 lo sitúa en torno a 1497.

9 Para Clair (1998:117), la actividad de Juan Vázquez podría haber comenzado los últimos meses de 1483. Por su parte, Odriozola (1982: 149) lo sitúa entre 1482 y 1491, si bien la primera obra que le atribuye presenta una datación incierta, en torno a 1483. Obra que el ISTC is00570500 sitúa actualmente antes del 4 de mayo de 1484, mientras que el GW 4710 mantiene este mismo límite, aunque señala que muy probablemente se imprimió antes del 28 de marzo de ese mismo año.

10 Véase, para la versión en castellano ISTC ia00374600 y GW 00063, y para la cédula en catalán GW 00064 y ISTC ia00374700. La versión catalana fue descrita y reproducida por Rubió (1993: 308-310). Téngase en cuenta que de la versión castellana no se conserva actualmente ningún ejemplar, si bien, cuando Konrad Haebler compila la primera parte de su Bibliografía Ibérica, describe esta pieza a partir de un ejemplar perteneciente a una colección particular de Madrid (Haebler 1903: 45, no 101), que fue reproducido posteriormente por el mismo autor (Haebler 1923: 222). La misma reproducción fue incluida en su obra por Vindel (1945-1951: VI, 84, no 19).

11 ISTC is00569800, GW 46. Desde este último repertorio se puede acceder al ejemplar digitalizado que custodia la Real Academia de la Historia. Este ejemplar, el único conservado, fue ya reproducido por Pérez Pastor (1887: 3).

12 ISTC is00570800, GW 49. Como en el caso anterior, a partir del enlace de este repertorio se puede ver el ejemplar

SCRIPTA, Revista internacional de literatura i cultura medieval i moderna, núm. 5 / juny 2015 / pp. 93 - 104 ISSN: 2340-4841 · doi:10.7203/SCRIPTA.5.5164 
José Vicente Boscá Codina \& María Luz Mandingorra Llavata. Hallazgo de una bula incunable desconocida en la catedral de Valencia. Contribución a la imprenta de Antonio Téllez (Toledo, 1495)

formales es muy similar. En cambio, sí se advierte una total coincidencia material entre las bulas impresas en una misma lengua. ${ }^{13}$ Bien es verdad que, en el caso de la fórmula para difuntos, no podemos establecer comparación alguna entre las bulas en lengua castellana, ya que sólo se conoce una. ${ }^{14}$ Por lo que respecta a las escritas en catalán, aunque se advierte una cierta similitud formal, difieren en el encabezado, ya que sólo una de las dos conservadas presenta la misma inicial xilográfica que aparece en las bulas para vivos, ${ }^{15}$ no así en el caso de la otra. ${ }^{16}$

A propósito del lugar en el que físicamente se imprimieron todas estas bulas, Antonio Odriozola sugirió que, tanto las de Juan Vázquez como las de Antonio Téllez, fueron impresas en el Monasterio de San Pedro Mártir, de Toledo. Concretamente, sobre las atribuidas a Téllez, este autor apuntaba que podrían estar relacionadas con el privilegio concedido a dicho monasterio para la impresión de las bulas de Cruzada. No obstante, Ramón Gonzálvez Ruíz (1986: 158 y 163-164), pese a que casi la totalidad de las bulas de Cruzada impresas hasta el año 1500 proceden del Monasterio de San Pedro Mártir, duda de la existencia de un privilegio concedido a este cenobio toledano con anterioridad a la cédula real de 1501, de la que ya diera noticia Pérez Pastor. Más allá de la estricta impresión de las bulas de Cruzada, Odriozola (1982: 149 y 171-172) llegaba a plantear incluso la hipótesis de que Antonio Téllez tuviese instalado su taller en el propio monasterio. En cualquier caso, se trata de una imprenta a la que se atribuye una escasa producción, distribuida en un periodo de cuatro años y que, junto a las bulas de indulgencias mencionadas, se cifra en un libro que cuenta con colofón completo, ${ }^{17}$ dos libros cuya autoría no se discute, aunque carecen de indicación de tipógrafo ${ }^{18}$ y un cuarto libro cuya atribución a este impresor no resulta unánime. ${ }^{19}$

digitalizado de la Real Academia de la Historia. El ejemplar conservado en la Biblioteca de Catalunya fue reproducido por Rubió (1993: 302, fig. 9).

13 Para las bulas en castellano ver ISTC is00569800, GW 46 (véase nota 11); ISTC is00570500, GW 4710 (desde este repertorio se puede acceder al ejemplar que conserva la Biblioteca Nacional de Madrid); ISTC is00572600 (reproducida por Gonzálvez, 1986: 174, fig. 5). Por lo que respecta a las bulas en catalán, ver ISTC is00570800, GW 49 (véase nota 12); ISTC is00570700, GW 48. Desde este último repertorio se puede acceder al ejemplar conservado en la Biblioteca de Catalunya, que ya fuera reproducido por Rubió (1993: 300, fig. 8).

14 ISTC is00572900, GW 50.

15 ISTC is00569600, GW 45. Se puede acceder, desde este repertorio, al ejemplar digitalizado que conserva la Biblioteca de Catalunya. Fue reproducida por Rubió (1993: 298, fig. 7).

16 ISTC is00569400, GW 44. Reproducida igualmente por Rubió (1993: 298, fig. 6).

17 Véase más arriba la referencia correspondiente en la nota 2.

18 Gutiérrez, Julián. De potu in lapidis preservatione. Toledo: [Antonio Téllez]. 29 marzo, 1494; 4º , véase GW 12103, ISTC ig00734500. Román, Comendador. Coplas a la muerte del príncipe Don Juan. [Toledo: Antonio Téllez, ca. 1498]; Fol., véase GW M38836, ISTC ir00306000. La discusión a propósito de la datación de esta última obra puede verse en la nota 8.

19 Se trata del Tractatus brevis de articulis fidei de Iohannes Alexandrinus, atribuido por el ISTC ij00249000 a Antonio Téllez y que habría sido impreso en torno a 1495. Tal y como señala esta base de datos, la información procede de la

SCRIPTA, Revista internacional de literatura i cultura medieval i moderna, núm. 5 / juny 2015 / pp. 93 - 104 ISSN: 2340-4841 · doi:10.7203/SCRIPTA.5.5164 
José Vicente Boscá Codina \& María Luz Mandingorra Llavata. Hallazgo de una bula incunable desconocida en la catedral de Valencia. Contribución a la imprenta de Antonio Téllez (Toledo, 1495)

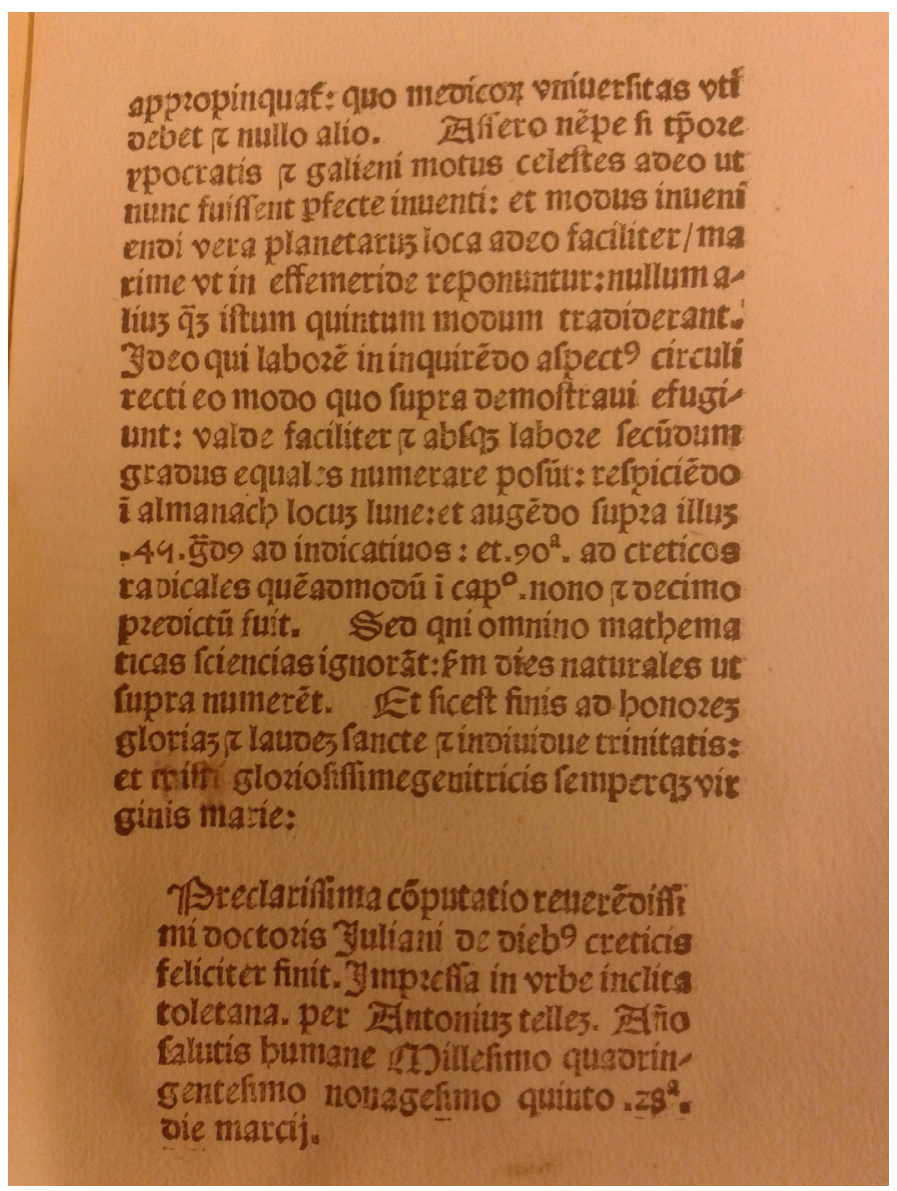

Fig. 1 Gutiérrez, Julián. De computatione dierum criticarum. Toledo: Antonio Téllez. 28 marzo, 1495; 4. Se reproduce la hoja correspondiente al colofón. Santiago de Compostela. Librería Conventual de San Francisco, Biblioteca Provincial, 34-2-24. ${ }^{20}$

\footnotetext{
anotación manuscrita de Frederick J. Norton presente en el catálogo de la British Library, aunque el British Museum Catalogue dudaba incluso de su origen hispano. Sin embargo, el GW M12804 responsabiliza de esta edición al impresor Alfonso Fernández de Córdoba, sitúa la impresión de la misma en Valencia y la data en torno a 1483-85. Por su parte, Francisco Vindel (1945-1951: VI, 348), a partir de Penney (1929: 137), sitúa la impresión de esta obra posiblemente en Híjar, hacia 1495, sin ofrecer indicación alguna de tipógrafo.
}

20 Agradecemos a D. Santiago Cepeda su amabilidad al proporcionarnos la reproducción fotográfica que aquí aparece. 
José Vicente Boscá Codina \& María Luz Mandingorra Llavata. Hallazgo de una bula incunable desconocida en la catedral de Valencia. Contribución a la imprenta de Antonio Téllez (Toledo, 1495)

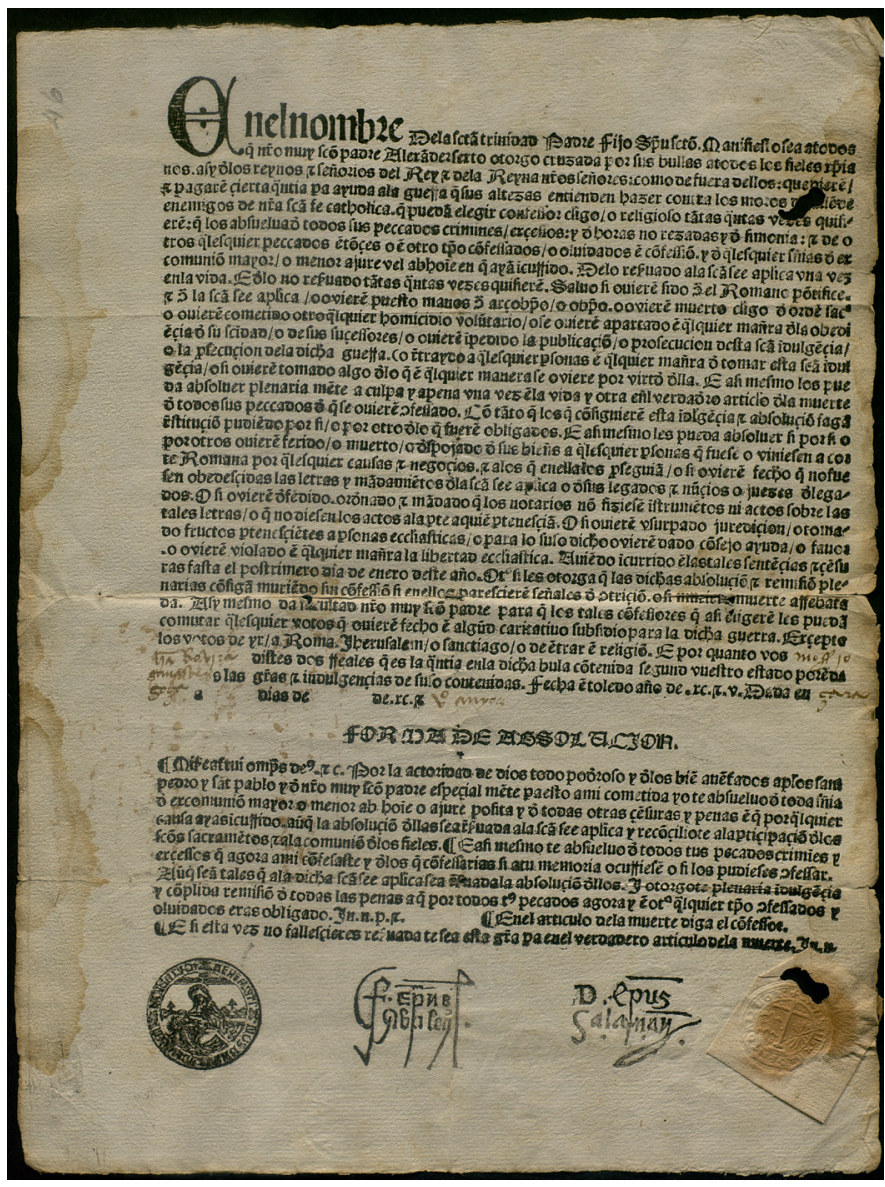

Fig. 2 Bula de indulgencias de la Santa Cruzada (para vivos, en castellano) [Toledo: Antonio Téllez, 1495]. Recto. Zaragoza. Archivo Histórico Provincial, DS/000070. 
José Vicente Boscá Codina \& María Luz Mandingorra Llavata. Hallazgo de una bula incunable desconocida en la catedral de Valencia. Contribución a la imprenta de Antonio Téllez (Toledo, 1495)

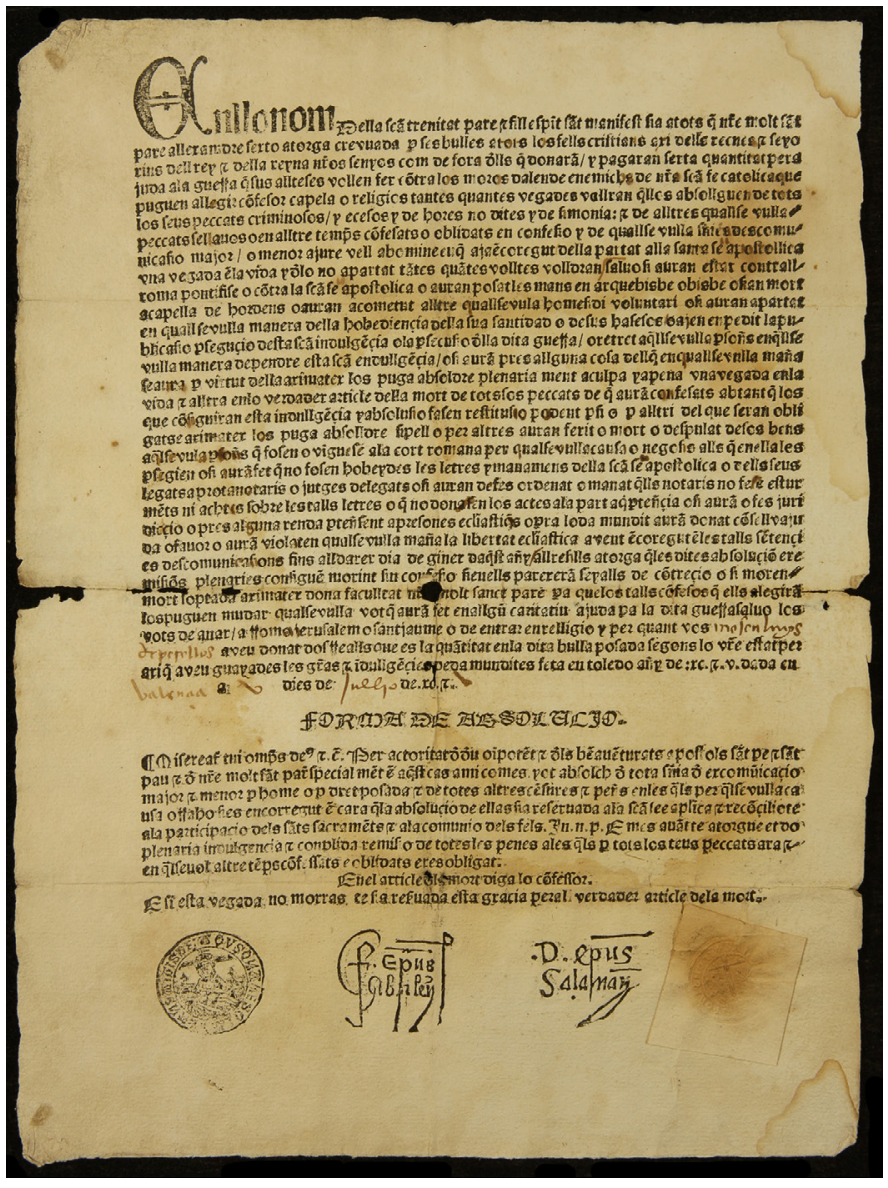

Fig. 3 Bula de indulgencias de la Santa Cruzada (para vivos, en catalán) [Toledo: Antonio Téllez, 1495].

Recto. Valencia, Archivo de la Catedral, legajo 6293-11. 
José Vicente Boscá Codina \& María Luz Mandingorra Llavata. Hallazgo de una bula incunable desconocida en la catedral de Valencia. Contribución a la imprenta de Antonio Téllez (Toledo, 1495)

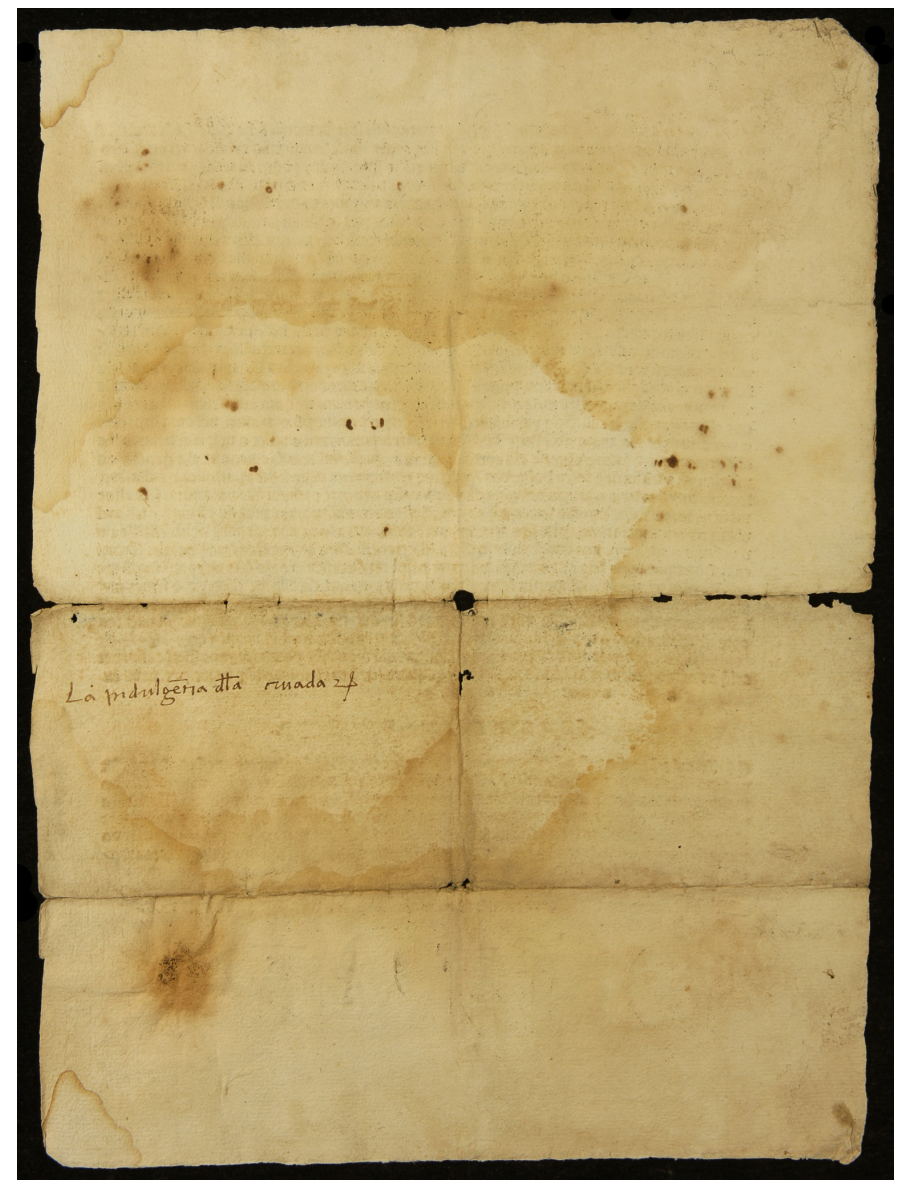

Fig. 4 Bula de indulgencias de la Santa Cruzada (para vivos, en catalán) [Toledo: Antonio Téllez, 1495]. Vuelto. 
José Vicente Boscá Codina \& María Luz Mandingorra Llavata. Hallazgo de una bula incunable desconocida en la catedral de Valencia. Contribución a la imprenta de Antonio Téllez (Toledo, 1495)

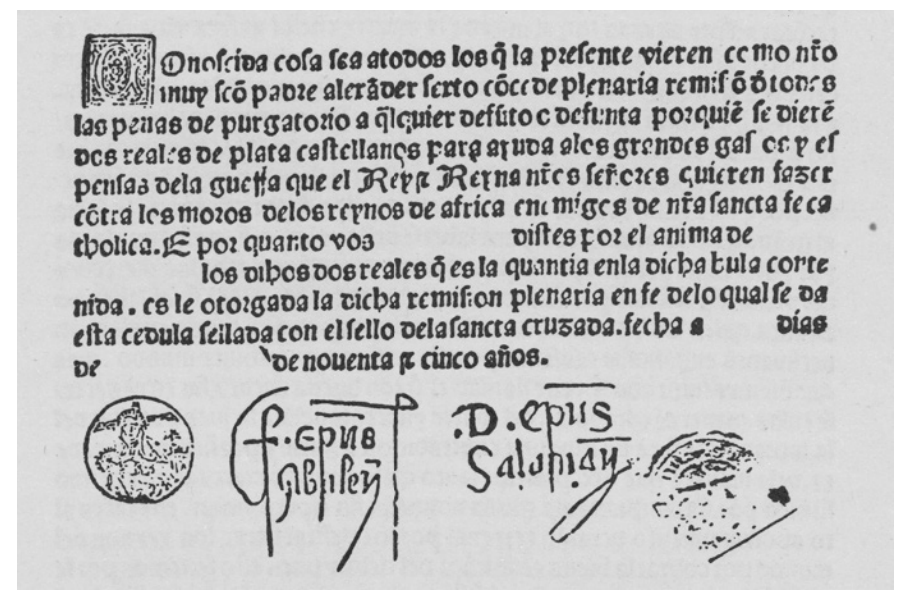

Fig. 5 Bula de indulgencias de la Santa Cruzada (para difuntos, cédula, en castellano). [Toledo: Antonio Téllez, 1495]. Apud: Haebler (1923: 222).

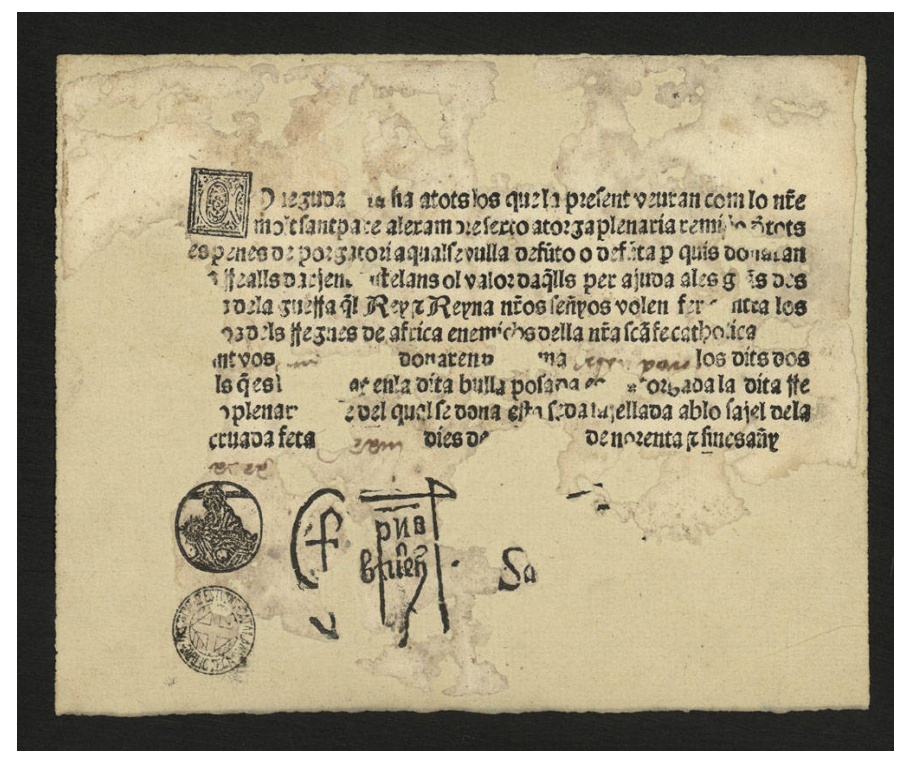

Fig. 6 Bula de indulgencias de la Santa Cruzada (para difuntos, cédula, en catalán). [Toledo: Antonio Téllez, 1495]. Barcelona. Biblioteca de Cataluña, Bu. 2- viII. 
José Vicente Boscá Codina \& María Luz Mandingorra Llavata. Hallazgo de una bula incunable desconocida en la catedral de Valencia. Contribución a la imprenta de Antonio Téllez (Toledo, 1495)

\section{Bibliografía citada}

Clair, C. (1998) Historia de la imprenta en Europa. Edición y prólogo de Julián Martín Abad, Madrid, Ollero y Ramos. [Trad. cast. de A history of European Printing, London, Academic Press, 1976].

Delgado Casado, J. (1996) Diccionario de impresores españoles (Siglos XV-XVII), Madrid, Arco Libros, 2 vol.

Einblattdrucke (1914) Einblattdrucke des XV. Jabrbunderts. Ein bibliographisches Verzeichnis. Herausgegeben von der Kommission für den Gesamtkatalog der Wiegendrucke, Halle A. S., Ehrhardt Karras G.M.B.H.

Eubel, C. (1914) Hierarchia catholica Medii Aevi sive summorum pontificum, S.R.E. cardinalium, ecclesiarum antistitum series ab anno 1431 usque ad annum 1503 perducta e documentis tabularii praesertim Vaticani collecta, digesta, edita per Conradum Eubel, Monasterii, Sumptibus et Typis Librariae Regensbergianae.

García Craviotto, F. (1988) «La imprenta incunable de Alfonso Fernández de Córdoba: aportación al problema de Híjar o Valencia en su última época atribuida», en López Vidriero, M ${ }^{\mathrm{a}} \mathrm{L} . /$ Cátedra, P.M. (eds.) El libro antiguo español. Actas del primer Coloquio Internacional (Madrid, 18 al 20 de diciembre de 1986), Salamanca, Universidad de Salamanca/Biblioteca Nacional de Madrid/ Sociedad Española de Historia del libro, pp. 155-173.

Gesamtkatalog. Gesamtkatalog der Wiegendrucke (disponible en http://www. gesamtkatalogderwiegendrucke.de/).

Gonzálvez Ruiz, R. (1986) «Las bulas de la Catedral de Toledo y la imprenta incunable castellana», Boletín de la Real Academia de Bellas Artes y Ciencias Historicas de Toledo, 18, 9-180.

Haebler, K. (1903) Bibliografía ibérica del siglo XV. Enumeración de todos los libros impresos en España y Portugal hasta el año 1500, con notas críticas, La Haya/Leipzig, Martinus Nijhoff/Karl W. Hiersemann. [Reimpr. facsímil: Madrid, Julio Ollero, 1992].

—. (1917) Bibliografía ibérica del siglo XV. Segunda parte, La Haya/Leipzig, Martinus Nijhoff/Karl W. Hiersemann. [Reimpr. facsímil: Madrid, Julio Ollero, 1992].

—. (1923) Geschichte des spanischen Frühdruckes in Stammbäumen, Leipzig, Karl W. Hiersemann.

Incunabula. Incunabula Short Title Catalogue (disponible en http://www.bl.uk/catalogues/istc/).

Odriozola, A. (1982) «La imprenta en Castilla en el siglo XV», en VV.AA., Historia de la imprenta bispana, Madrid, Editora Nacional, pp. 91-219.

Penney, C.L. (1929) List of Books printed before 1601, in the Library of the Hispanic Society of America. Compiled by..., New York, Hispanic Society of America.

Pérez Pastor, C. (1887) La imprenta en Toledo. Descripción bibliográfica de las obras impresas en la imperial ciudad desde 1483 hasta nuestros días, Madrid, Imprenta y Fundición de Manuel Tello Impresor de Cámara de S.M.

Pons Alós, V./Cárcel Ortí, Ma M. (2005) «Los canónigos de la Catedral de Valencia (1375-1520).

SCRIPTA, Revista internacional de literatura i cultura medieval i moderna, núm. 5 / juny 2015 / pp. 93 - 104 
José Vicente Boscá Codina \& María Luz Mandingorra Llavata. Hallazgo de una bula incunable desconocida en la catedral de Valencia. Contribución a la imprenta de Antonio Téllez (Toledo, 1495)

Aproximación a su prosopografía», Anuario de Estudios Medievales, 35/2, pp. 907-950.

Rubió i Balaguer, J. (1993) «Noves butlles catalanes incunables», en Rubió i Balaguer, J. Llibreters $i$ impressors a la Corona d‘Aragó, Barcelona, Publicacions de l'Abadia de Montserrat, pp. 281-322. [Es reimpr. de «Noves butlles catalanes incunables», Butlleti de la Biblioteca de Catalunya, 6 (1920-22), pp. 5-23].

Velasco de la Peña, E./Egea Gilaberte, J.F. (1985) «Sobre la imprenta del siglo XV en España: un nuevo incunable localizado», Boletín del Museo e Instituto «Camón Azunar», 22, pp. 97-99.

Vindel, F. (1945-1951) El arte tipográfico en España durante el siglo XV, Madrid, Ministerio de Asuntos Exteriores/Dirección General de Relaciones Culturales, 9 vol. 